Check for updates

Cite this: RSC Adv., 2019, 9, 10715

Received 29th January 2019

Accepted 22nd March 2019

DOI: $10.1039 / c 9 r a 00787 c$

rsc.li/rsc-advances

\section{Performance evaluation of interfacial polymerisation-fabricated aquaporin-based biomimetic membranes in forward osmosis}

\author{
Zhixia Liang, (D) ${ }^{a}$ Yanbin Yun, (D) *a Manxiang Wang, (D) *b Guicheng Liu, (D) ${ }^{c}$ \\ Peng Lu, (D) ${ }^{d}$ Woochul Yang ${ }^{c}$ and Chunli Li ${ }^{d}$
}

Aquaporins play a promising role in the fabrication of high-performance biomimetic membranes. Interfacial polymerisation is a promising strategy for synthesizing aquaporin-based membranes. In this study, robust and high-performance aquaporin-based biomimetic membranes were successfully fabricated by interfacial polymerisation, and the membrane separation performance and interfacial polymerisation method were systematically evaluated. The effects of modification methods on the performance of aquaporins-based biomimetic membranes, including sodium hypochlorite and thermal post-treatment, protein-to-lipid ratio, liposome concentration and the addition arrangement of aquaporins were also investigated. Morphological observation suggested that the introduced proteoliposomes were completely embedded in the polyamide layer and that their spherical shape was preserved. Sodium hypochlorite post-treatment and thermal treatment were beneficial in improving the water flux and salt rejection of the resultant membrane without sacrificing the aquaporin activity. The biomimetic membranes had a high water flux and salt rejection, which were almost twice that of the control membranes, after aquaporin-based proteoliposomes were incorporated with an appropriated proteinto-lipid ratio and liposome concentration. The addition arrangement of aquaporins during the interfacial polymerisation procedure significantly influence the obtained membrane's structure. Lastly, this article introduces valuable and systematic research on interfacial polymerisation fabricated aquaporin-based biomimetic membranes with outstanding separation performance.

\section{Introduction}

With the globally increasing scarcity of clean water, the development of high-performance membranes for water desalination and reuse applications has become an important objective. Today, the most robust and widely used desalination technology is the reverse osmosis (RO) process. RO desalination is a typical pressure-driven process, in which an external hydraulic pressure is applied as a driving force and solutes are excluded by a semipermeable membrane (an RO membrane). It is a thermodynamically non-spontaneous process, where transmembrane pressure is essential to provide the driving force for mass transport across the membrane. ${ }^{1}$ Current RO desalination plants consume approximately 3-6 kW h energy to produce $1 \mathrm{~m}^{3}$ of fresh water,

\footnotetext{
${ }^{a}$ School of Environmental Science and Engineering, Beijing Forestry University, Beijing 100083, China. E-mail: yunyanbin@bjfu.edu.cn

${ }^{b}$ Center for Energy Storage Research, Green City Research Institute, Korea Institute of Science and Technology (KIST), Hwarang-ro 14-gil 5, Seongbuk-gu, Seoul 02792, Republic of Korea. E-mail: wmx8866@163.com

${ }^{c}$ Department of Physics, Dongguk University, Seoul 04620, Republic of Korea

${ }^{d}$ College of Material Science and Chemical Engineering, Ningbo University, Zhejiang 315211, China
}

depending on feed salinity and energy source or recovery. To this end, RO is still considered an energy and cost intensive process despite the fact that the low energy consumption has already been realized by advances in the technology. ${ }^{2}$ Forward osmosis (FO) for desalination emerges with the promise of overcoming the challenges of pressure-driven membrane processes. FO offers recognized advantages including high rejections to contaminants, low membrane fouling and potentially less operation energy. Due to these reasons, FO has attracted immense attention over the past decade and significant progress has been made in the FO technology. ${ }^{3}$ The design and fabrication of highperformance forward osmosis membranes with high water permeabilities that do not sacrifice their salt rejection properties and excellent chemical stability are key challenges. ${ }^{4}$

Recently, developments in the membrane field have focused on thin-film composite membranes composed of thin selective layers and porous support materials. Reactive monomers and additives used during polycondensation have been adjusted to increase membrane selectivity or permeance during the design of the selective layer. ${ }^{5-7}$ The incorporation of biological proteins into the membrane selective layer is a more challenging and innovative attempt. ${ }^{8,9}$ 
Aquaporins (AQPs) are a large family of water-transport proteins in cells, which exhibit unique properties including high permeabilities (as many as 3 billion water molecules per second per subunit) and superior selectivities (only allowing the passage of water while rejecting all other molecules). ${ }^{\mathbf{1 0 , 1 1}}$ Their unique selectivities and high water transport capabilities are attractive for possible use in membrane application. Inspired by this, aquaporin-based biomimetic membranes (ABMs) have attracted extensive worldwide research interest in recent years. ${ }^{12-14}$ The water permeabilities of AQP-incorporated polymer membranes are at least an order of magnitude higher than those of commercial RO membranes, and the membranes are capable of rejecting all other solutes. ${ }^{15,16}$

Various strategies for the preparation of ABMs have been reported. The selective layers of previously reported ABMs were prepared by directly fusing or collapsing AQPs-incorporated liposomes onto porous substrates or membrane surfaces. ${ }^{\mathbf{1 7 - 1 9}}$ However, most of the membranes fabricated by this method exhibit relatively low $\mathrm{NaCl}$ retention, which renders them unusable for forward osmosis due to draw-solute loss and low feed-solute rejection. Maintaining the activity of AQPs in the external environment and reducing defect formation in the selective layer remain challenging tasks in the preparation of high-performance ABMs. The immobilisation of AQPscontaining vesicles in a dense polymer layer has recently been investigated as a way of preserving the properties and integrity of the vesicles. ${ }^{\mathbf{2 0} 21}$ In this approach, interfacial polymerisation and polymer cross-linking, layer-by-layer assembly, UV polymerisation, and surface imprinting are the most widely used methods. ${ }^{22-25}$ Among these methods, interfacial polymerisation is a compact fabrication process that provides attractive mechanical stability and allows easy scale up, which is a critical step toward the adoption of biomimetic membranes in various applications. ${ }^{26,27}$

Despite this, defect formation in the extremely thin selective layer composed of lipids remained a challenge in the preparation of a biomimetic membrane with good performance. In the present study, we propose several modification for fabricating high-performance AQP-based membranes by interfacial polymerisation, including the addition arrangement of aquaporins, sodium hypochlorite and thermal post-treatment, protein-tolipid ratio and liposome concentration. The effects of modification methods on the membrane characteristic and separation performance were systematically investigated.

\section{Experimental}

\section{Materials}

1,2-Dioleoyl-sn-glycero-3-phosphocholine (DOPC, purity > 99\%) and $n$-octyl- $b$-D-glucopyranoside (OG, purity > 99\%) were purchased from Aladdin (China). AQP1 (Recombinant Human Aquaporin-1, partial CSB-EP001957HU) was purchased from Wuhan Huamei Bioengineering Co., Ltd. (China). Polysulfone (PSf, Mn: $26000 \mathrm{Da}$ ), $N$-methylpyrrolidone (NMP, anhydrous, 99.5\%), PEG400 (powder, 99\%), and LiCl (powder, 99\%) were used to prepare the porous polysulfone substrate. 1,3-Phenylenediamine (MPD, 99\%) and 1,3,5-benzenetricarbonyl trichloride (TMC, 98\%) were used to form the thin selective layer. Sodium chloride ( $\mathrm{NaCl}$, crystals, ACS reagent, Sinopharm Chemical Reagent Co., Ltd.) was dissolved in deionised (DI) water for use in the membrane performance test. All the other chemicals used in the present study were purchased from Sigma-Aldrich (China). DI water with a resistivity of $18.2 \mathrm{M} \Omega \mathrm{cm}$ supplied by a Millipore integral water purification system was used to prepare buffer solutions and for the forward osmosis experiments. Phosphate buffer ( $\mathrm{pH} 7.4,0.1 \mathrm{mM}$ ) was used to prepare the proteoliposomes and biomimetic membranes.

\section{Preparation of AQP1 proteoliposomes}

Proteoliposome vesicles were prepared by the film hydration and extrusion method. ${ }^{28,29}$ Ten milligrams of DOPC was dissolved in $0.5 \mathrm{~mL}$ of chloroform and evaporated under a stream of nitrogen gas to form a thin lipid film. The resulting film was stored in a vacuum desiccator for at least $24 \mathrm{~h}$. An aliquot $(1 \mathrm{~mL})$ of phosphate buffered saline ( $\mathrm{pH}$ 7.4) was added to rehydrate the film, after which it was subjected to three freeze-thaw cycles. The resulting solution contained unilamellar liposomes. Liposomes with uniform size distributions were extruded 15 times through a $100 \mathrm{~nm}$-pore polycarbonate filter with a liposome extruder (LiposoEasy LE-15, China). To prepare AQP1containing proteoliposomes, AQP1 was incorporated into the liposomes by dialysis. The AQP1 solution was mixed with the liposome solution and 1\% OG (as a detergent) at a desired protein-to-lipid (P/L) mass ratio. The OG detergent was removed by dialysis against PBS buffer for $3 \mathrm{~d}$ at room temperature. Eventually, AQP1 was reconstituted into lipid vesicles.

\section{Preparation of AQP1-incorporated membranes}

Preparation of membrane substrates. Membrane substrates were prepared by the usual phase inversion method. Briefly, $12 \mathrm{~g}$ of PSf beads, $4 \mathrm{~g}$ of PEG400, and $2 \mathrm{~g}$ of LiCl were dissolved in $82 \mathrm{~g}$ of NMP, and the solution was stirred at room temperature for $8 \mathrm{~h}$. The PSf solution was cast onto a glass plate using a $100 \mu \mathrm{m}$ casting knife. The glass plate with the film was smoothly immersed into DI water at room temperature to form the polysulfone substrate.

Preparation of membrane-selective layer. The membraneselective layer was synthesised by interfacial polymerisation. The PSf substrate was first soaked in a mixture solution containing 3.4 wt\% MPD and a certain amount of AQP1-based proteoliposomes for $2 \mathrm{~min}$. An air knife was then used to remove excess solution from the membrane surface with compressed nitrogen gas. TMC dissolved in hexane (0.15 wt\%) was gently poured onto the substrate surface for $1 \mathrm{~min}$ to form the selective layer. The composite membranes were cured in DI water at $70{ }^{\circ} \mathrm{C}$ for $5 \mathrm{~min}$ and post-treated using $4.5 \mathrm{~g} \mathrm{~L}^{-1} \mathrm{NaOCl}$ (available chlorine $8-12 \%$ ) for $5 \mathrm{~min}$ to further improve the membrane water permeability (unless otherwise specified). This was followed by rinsing with a 1000 ppm $\mathrm{NaHSO}_{3}$ aqueous solution for $30 \mathrm{~s}$ and subsequent heat-curing at $70{ }^{\circ} \mathrm{C}$ for $10 \mathrm{~min}$. The resultant membranes were denoted as ABM-1 and soaked in deionised water for further application. In addition, a PSf substrate was first soaked in MPD solution, and after 
removing the excess aqueous solution, proteoliposomes were subsequently pumped on the membrane; the excess aqueous solution was removed by gentle sweeping before the TMC solution contacted and reacted with the MPD to form a proteoliposome-embedded three-dimensionally crosslinked polyamide layer. The membranes prepared in this manner were referred to as ABM-2. Control membranes denoted as ABM-10 and $A B M-2-0$, respectively, were prepared in the same way but with liposomes instead of proteoliposomes. The fabrication procedure is illustrated in Fig. 1.

\section{Characterizing the proteoliposomes and membranes}

The sizes of the liposome and proteoliposome vesicles were determined using a Nano Zetasizer light-scattering nanometer (NanoZS, Malvern Instruments Ltd., UK), and the water permeability was determined using an SX20 stopped-flow spectrometer (Applied Photophysics PiStar180, UK). In brief, vesicles were diluted to $1 \mathrm{mg} \mathrm{mL} \mathrm{mL}^{-1}$ and extruded with a $100 \mathrm{~nm}$ polycarbonate filter prior to testing. During the stopped-flow experiments, vesicles were rapidly mixed with $75 \mathrm{~mL}$ of liposome or proteoliposome solution and an equal volume of $500 \mathrm{mM}$ sucrose in the same buffer (10 mM PBS, pH 7.4). The vesicle volume decreased and the light-scattering signal increased as result of water transport out of the vesicles under osmotic pressure. The data were processed with Origin software and fitted to the following exponential rise equation: ${ }^{30}$

$$
Y=A \exp (-k t)
$$

where $Y$ is the signal intensity, $t$ is the elapsed time (s), and $k$ is the relative rate of water conduction $\left(\mathrm{s}^{-1}\right)$. Water permeability $\left(P_{\mathrm{f}}\right)$ was calculation using the following equation: ${ }^{30}$

$$
P_{\mathrm{f}}=\frac{k}{\left(S / V_{0}\right) V_{\mathrm{w}} \Delta_{\mathrm{osm}}},
$$

where $S / V_{0}$ is the ratio of the surface area to the initial volume of the vesicle, $V_{\mathrm{w}}$ is the partial molar volume of water $(0.018 \mathrm{~L}$ $\mathrm{mol}^{-1}$ ), and $\Delta_{\mathrm{osm}}$ is the difference in osmolarity between the intravascular and extravehicular aqueous solutions.

\section{Membrane characterisation}

Microscopic characterisation. The membranes were dried in a vacuum desiccator for $24 \mathrm{~h}$ prior to microscopic characterisation. The top surfaces and cross sections were examined by scanning electron microscopy (SEM, FEI, Quanta 200, Holland). Prior to examination, the membranes were fractured in liquid nitrogen and coated with gold using a sputter coater (MC IOOO ION SPUTTER). The surface roughness was determined by atomic force microscopy (AFM, NanoScope V MultiMode8, Bruker). The mean roughness $\left(R_{\mathrm{a}}\right)$ of the image in the range of 5 $\mu \mathrm{m}$ was used to characterise the membrane surface.

Evaluation of forward osmosis performance. Water flux $\left(J_{\mathrm{w}}\right)$ and reverse solute flux $\left(J_{\mathrm{s}}\right)$ were measured using a lab-scale cross-flow forward osmosis unit. The cross-flow filtration unit included a cell with a $2 \mathrm{~cm}^{2}$ effective membrane, and $1 \mathrm{M} \mathrm{NaCl}$ solution and DI water were used as the draw solution and feed, respectively. The average cross-flow velocity was $0.013 \mathrm{~m} \mathrm{~s}^{-1}$. The membranes were tested in the forward osmosis mode in which the feed solution faces the selective layer. A balance and a conductivity meter were used to record weight and conductivity changes. $J_{\mathrm{w}}$ and $J_{\mathrm{s}}$ values were calculated from eqn (3) and (4), respectively: ${ }^{31}$

$$
J_{\mathrm{w}}=\frac{\Delta V}{A \Delta t},
$$

where $J_{\mathrm{w}}$ is the water flux $\left(\mathrm{L} \mathrm{m}^{-2} \mathrm{~h}^{-1}\right), \Delta V(\mathrm{~L})$ is the volume change of the draw solution over a predetermined time $\Delta t(\mathrm{~h})$, and $A$ is the effective membrane surface area $\left(\mathrm{m}^{2}\right){ }^{31}$

$$
J_{\mathrm{s}}=\frac{\Delta C_{\mathrm{f}} V_{\mathrm{f}}}{A \Delta t},
$$

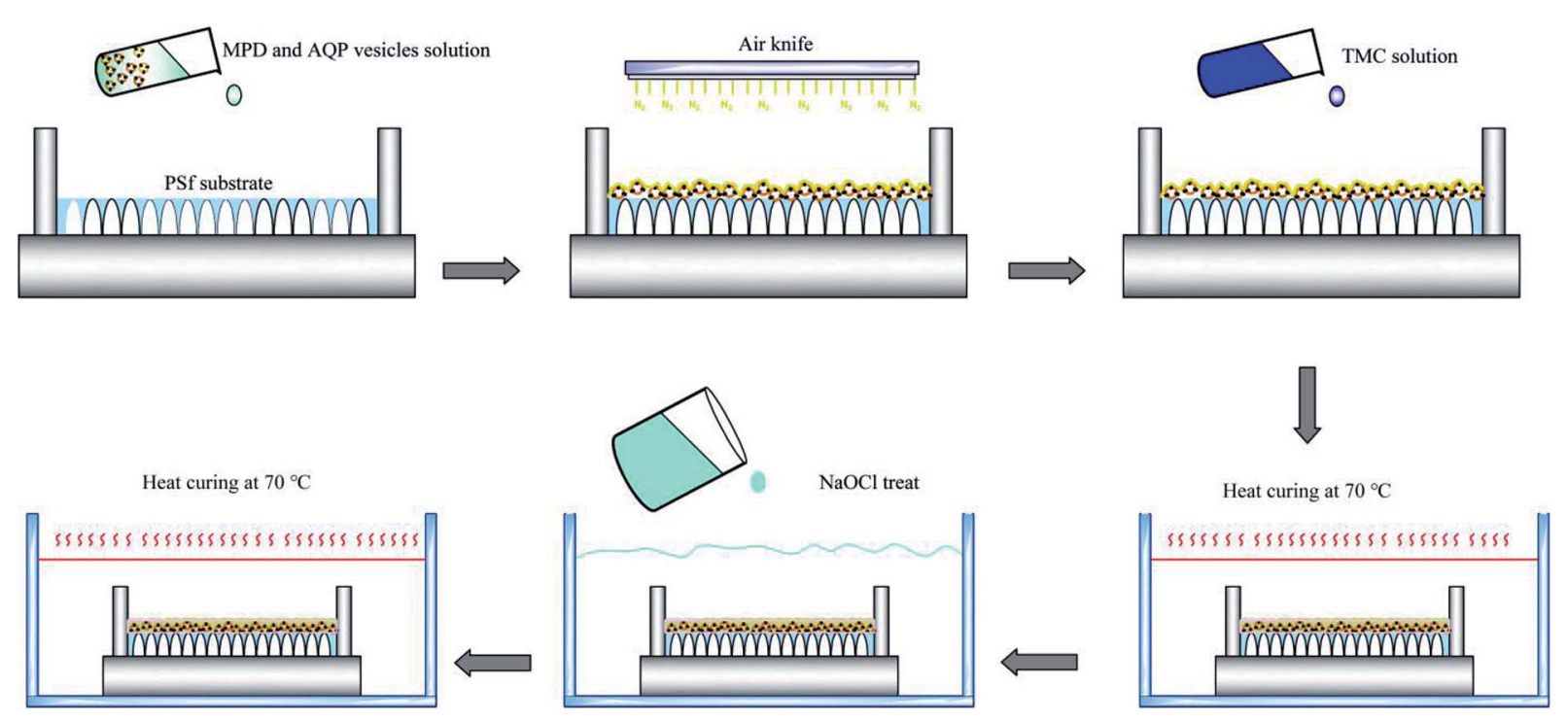

Fig. 1 Schematic depicting formation of aquaporin-1-based biomimetic membranes by interfacial polymerisation. 
Table 1 Properties of DOPC liposomes and AQP1-containing proteoliposomes $(P / L=1 / 200)$

\begin{tabular}{|c|c|c|c|c|}
\hline Samples & Vesicle diameter (nm) & Polydispersity index (PDI) & Rate constant $\left(\mathrm{s}^{-1}\right)$ & Water permeability $\left(\mu \mathrm{m} \mathrm{s}^{-1}\right)$ \\
\hline DOPC liposomes & $95.86 \pm 0.82$ & $0.11 \pm 0.01$ & $16.63 \pm 0.17$ & 39.85 \\
\hline AQP1-containing proteoliposomes & $92.12 \pm 0.75$ & $0.14 \pm 0.02$ & $131.59 \pm 0.23$ & 315.38 \\
\hline
\end{tabular}

where $J_{\mathrm{s}}$ is the reverse salt flux $\left(\mathrm{g} \mathrm{m}^{-2} \mathrm{~h}^{-1}\right), \Delta C_{\mathrm{f}}$ is the concentration change of the feed solution, $V_{\mathrm{f}}$ is the volume of the feed solution, $A\left(\mathrm{~m}^{2}\right)$ is the available membrane area, and $\Delta t(\mathrm{~h})$ is the effective testing time. The salt quality was calculated using a standard curve established prior to the experiments.

Determination of membrane transport and structural parameters. The water and solute permeability coefficients $(A$ and $B$, respectively) and the structural parameter $(S)$ were determined using the Excel-based algorithm developed by Tiraferri et $_{\text {al. }}{ }^{32}$ These three intrinsic parameters can be used with their respective governing equations to accurately predict the water flux and salt flux performances of a membrane in any laboratory-scale forward osmosis system. Four stages of forward osmosis experiments were conducted, in which each stage corresponded to a special draw solution concentration. The $A$, $B$, and $S$ values of the forward osmosis membranes were simultaneous determined from eqn (5) and (6)..$^{32}$

$$
\begin{aligned}
& J_{\mathrm{w}}=A\left\{\frac{\pi_{\mathrm{D}} \exp \left(-\frac{J_{\mathrm{w}} S}{D}\right)-\pi_{\mathrm{F}}}{1+\frac{B}{J_{\mathrm{w}}}\left[1-\exp \left(-\frac{J_{\mathrm{w}} S}{D}\right)\right]}\right\} \\
& J_{\mathrm{s}}=B\left\{\frac{C_{\mathrm{D}} \exp \left(-\frac{J_{\mathrm{w}} S}{D}\right)-C_{\mathrm{F}}}{1+\frac{B}{J_{\mathrm{w}}}\left[1-\exp \left(-\frac{J_{\mathrm{w}} S}{D}\right)\right]}\right\}
\end{aligned}
$$

Here, $D$ is the bulk diffusion coefficient of the draw salt, $\pi_{\mathrm{D}}$ and $\pi_{\mathrm{F}}$ are the osmotic pressures of the draw and feed solutions, respectively, and $C_{\mathrm{D}}$ and $C_{\mathrm{F}}$ are the concentrations of the draw and feed solutions, respectively.

\section{Results and discussion}

\section{Characterisation of liposomes and proteoliposomes}

Table 1 summarises the sizes and water permeabilities of the DOPC liposomes and proteoliposomes. The vesicles were in the size range of 90-95 $\mathrm{nm}$ and exhibited consistently small polydispersity indices, indicating a narrow size distribution. The osmotic water permeabilities of the vesicles were examined by stopped-flow spectrometry. Fig. 2 reveals that the DOPC liposomes have a smaller rate constant $\left(16.63 \mathrm{~s}^{-1}\right)$, which indicate that the lipid bilayers are relatively impermeable to water. In comparison, a much higher rate constant was determined for the AQP1-containing proteoliposomes. The corresponding water permeability of the proteoliposomes was determined as $315.38 \mu \mathrm{m} \mathrm{s}^{-1}$, which is almost an order of magnitude higher than that of the corresponding DOPC liposomes; this reveals



Fig. 2 Normalised light scattering stopped-flow kinetic curves of DOPC-based liposomes and proteoliposomes.

that the enhanced water permeability of the vesicles is attributable to the high water-transport abilities of the active waterchannel molecules in the lipid membrane.

\section{Morphologies of AQP1-based biomimetic membranes}

The surface morphologies of ABM-1, ABM-2, and the control membrane, which were prepared by the same procedure but without liposomes or proteoliposomes, were investigated by SEM and AFM, and the results are shown in Fig. 3 and 4, respectively. All the membranes show ridge-and-valley structures that are typical for polyamide-based forward osmosis membranes prepared using MPD and TMC. The sizes of the vesicles in the polyamide layer as determined by SEM are consistent with those measured by light scattering (Table 1), which indicates that the polyamide layer formed by interfacial polymerisation maintained the globular vesicle structure. Furthermore, it is observed that intact proteoliposomes are completely embedded in the polyamide selective layers (Fig. 3(d) and (e)), as excepted. The addition arrangement of aquaporins in producing ABMs appears to affect the surface morphology significantly. ABM-1 (Fig. 3(a) and (d)) appears to have fewer large visible pore openings compared with ABM-2, which may contribute to better water-permeability and membrane-fouling performance, or cleaning resistance during membrane processing. ${ }^{33}$

The surface roughness, as determined by AFM (Fig. 4), increased with the addition of proteoliposomes. The increases in membrane hydrophilicity, porosity, average surface pore diameter, mechanical strength, and thermal stability are related 

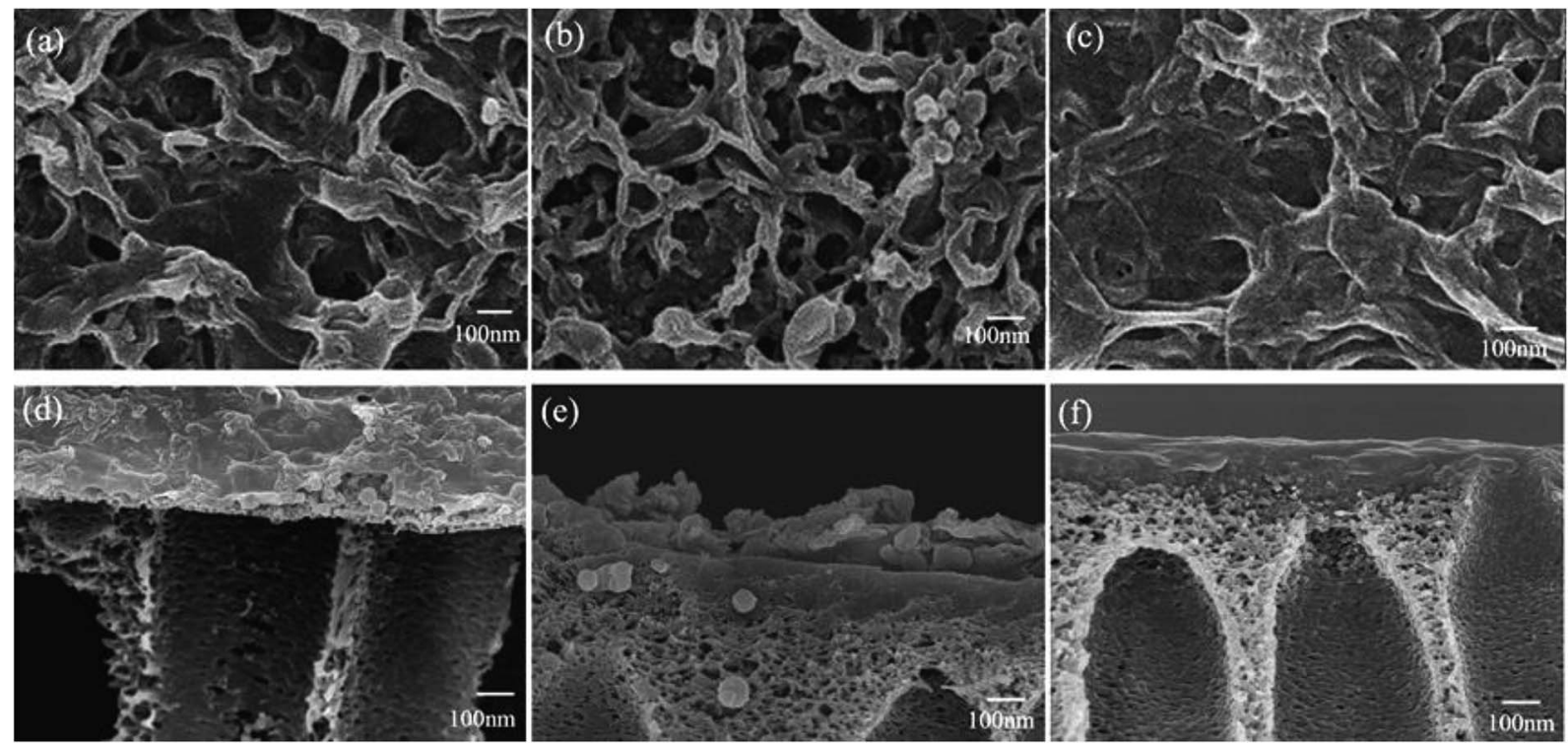

Fig. 3 SEM images of the top surface of (a) ABM-1, (b) ABM-2, and (c) control membrane. Cross-sectional SEM images of (d) ABM-1, (e) ABM-2, and (f) control membrane.

to the surface roughness. ${ }^{34,35}$ The rougher surfaces of ABM-1 and ABM-2 as revealed by AFM are attributed to the AQPcontaining vesicles. These AQP-incorporated structures provide better membrane permeability by preserving the original properties of the vesicles and their integrity, thereby affecting the roughness of the membrane active layer, which provides larger sites for foulant accumulation. ${ }^{36}$

\section{Separation properties}

Effect of AQP-based proteoliposomes on forward osmosis performance. Aquaporins are protein channels that permit the transport of up to a billion water molecules per second when a sufficiently high osmotic potential exists across the membrane. ${ }^{16}$ For the preparation of AQP-containing thin film composite PSf membranes, AQPs were embedded in DOPC liposomes. The effect of liposome and AQP-based proteoliposomes on the separation performance is displayed in Fig. 5. A notable decrease in water flux and an increase in reverse salt flux were observed for ABM-1-0 and ABM-2-0 with an increase in liposome concentration, which is explained by the observation that the lipid bilayer is impermeable to water. The liposomes act as nanoparticle additives during interfacial polymerisation, with the formation of defect resulting in considerable dilutive internal concentration polarisation in the selective membrane layer in the forward osmosis mode, which curtailed the net osmotic driving force across the membrane, thereby ensuring a reduced water flux. ${ }^{37,38}$ The water permeability of the membrane after the addition of proteoliposomes (ABM-1 and ABM-2) remarkably increased compared with the control group in which only the liposomes were embedded (ABM-1-0 and ABM-2-0). As shown in Fig. 5(b), the reverse salt flux increased proportionally with an increase in liposome or proteoliposome concentration. That is, enhancement in water (a)

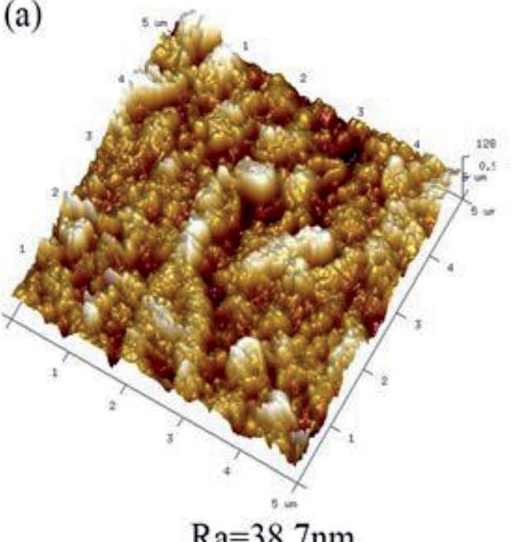

$\mathrm{Ra}=38.7 \mathrm{~nm}$

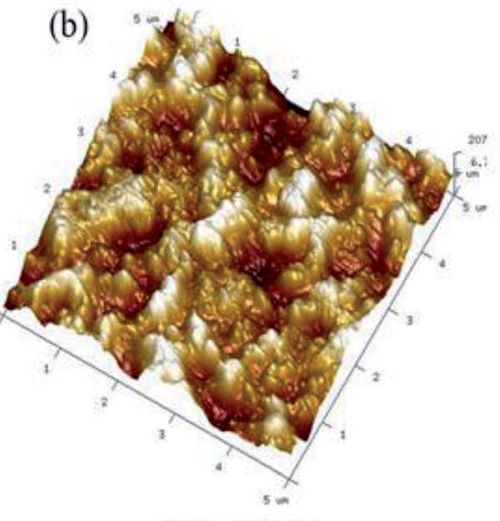

$\mathrm{Ra}=40.8 \mathrm{~nm}$ (c)



Fig. 4 AFM images of the top surfaces of (a) ABM-1, (b) ABM-2, and (c) control membrane. 

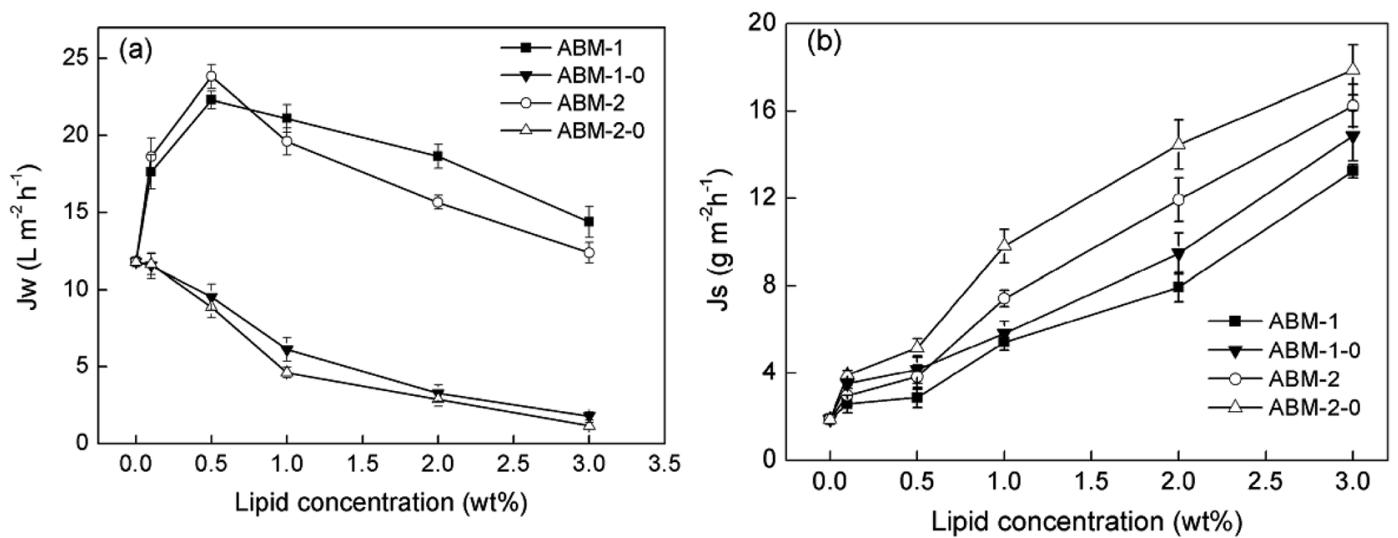

Fig. 5 Performances of ABM-1, ABM-2, and their control membranes with different liposome concentrations: (a) water flux and (b) reverse salt flux in the forward osmosis orientation (P/L value is $1: 200)$.

flux was not achieved by scarifying salt rejection. Based on the results, it could be concluded that the enhanced water permeability of the fabricated ABMs was owing to the incorporated AQPs.

Effect of AQP1-to-lipid weight ratio (P/L) on forward osmosis performance. The incorporated AQPs are known to enhance the water permeabilities of the proteoliposome; ${ }^{39}$ hence, the performance of $\mathrm{ABM}$ may benefit from further increase in the incorporated AQP1 density in the proteoliposome. Fig. 6 displays the performances of ABM- 1 and ABM- 2 with different $\mathrm{P} / \mathrm{L}$ values. An enhanced water flux was observed with increasing P/L for ABM-1 and ABM-2; however, when the AQP density increased to LPR 200, the water flux of the membranes decreased, while a high salt rejection was obtained. The initial enhancement in water flux at a high protein content is ascribable to the higher number of AQP1 units incorporated in the proteoliposomes, which facilitate the passing of more water molecules through the membrane. Meanwhile, further increases in $\mathrm{P} / \mathrm{L}$, packing defects, and pore defects in the biomimetic membrane led to lower water fluxes and separation effective. ${ }^{40,41}$ Hence, a P/L value of $1: 200$ is close to the optimal ratio for ABM-1 and ABM-2.
Effect of proteoliposomes concentration on forward osmosis performance. The separation performances of ABM- 1 and ABM2 with different proteoliposome concentrations are displayed in Fig. 7. Both ABM-1 and ABM-2 exhibit remarkable increases in water flux and reverse salt flux with increasing proteoliposome concentration; however, an increase in concentration beyond $0.5 \mathrm{mg} \mathrm{L}^{-1}$ resulted in a decrease in the water flux. The increments in water flux with increasing proteoliposome concentration can be understood by considering the fact that a plethora of channels are provided by AQP1 that facilitate the passing of water molecules through the biomimetic membranes. In this case, the advantages and drawbacks of both proteoliposomes and their polymeric 'protector' are shared. That is, the salt rejection of a liposome-based membrane might be less than that of a thin-film membrane because of defect formation during proteoliposome encapsulation into the selective layer, while the incorporation of AQP1 in the DOPC bilayer provides a large number of water channels that lead to a remarkable increase in water flux.

Effect of post-treatment on forward osmosis performance. $\mathrm{NaOCl}$ is used as a post-treatment reagent to improve the water
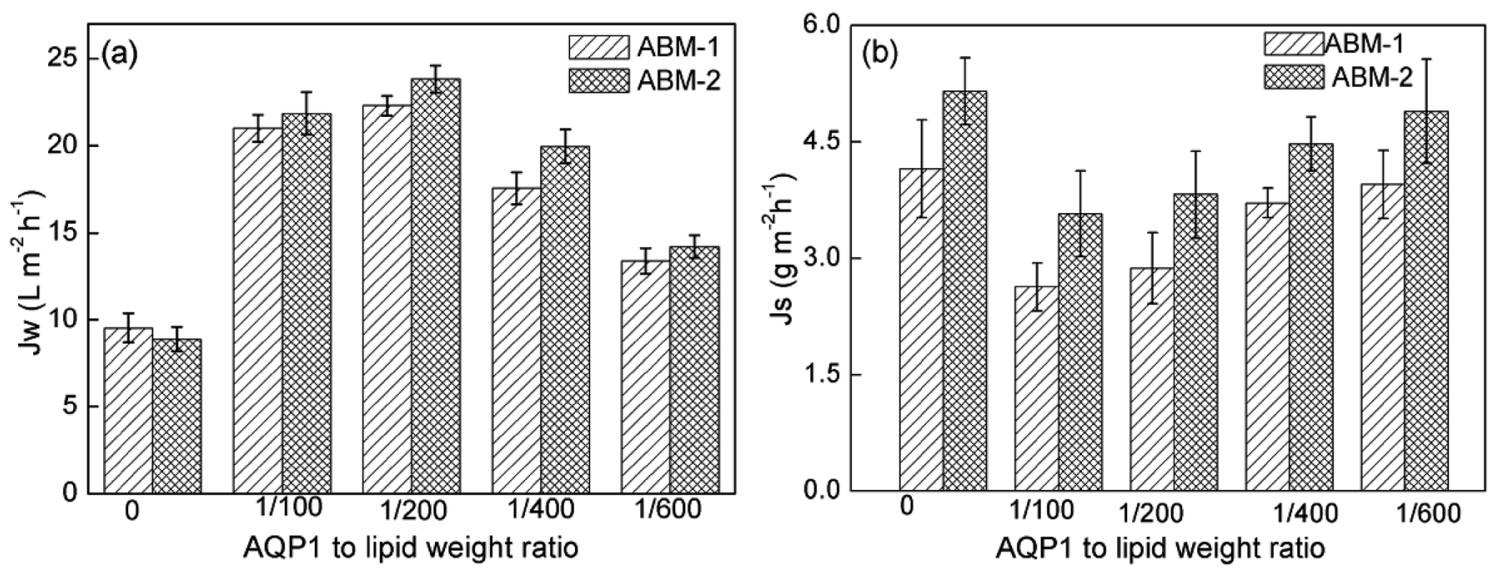

Fig. 6 Performance of AQP1-based membranes with various AQP1-to-lipid weight ratios (P/L) during forward osmotic testing: (a) water flux and (b) reverse salt flux (feed solution: $1 \mathrm{M} \mathrm{NaCl}$; draw solution: DI water; error bar: $\mathrm{SD}, n \geq 3$ ). 

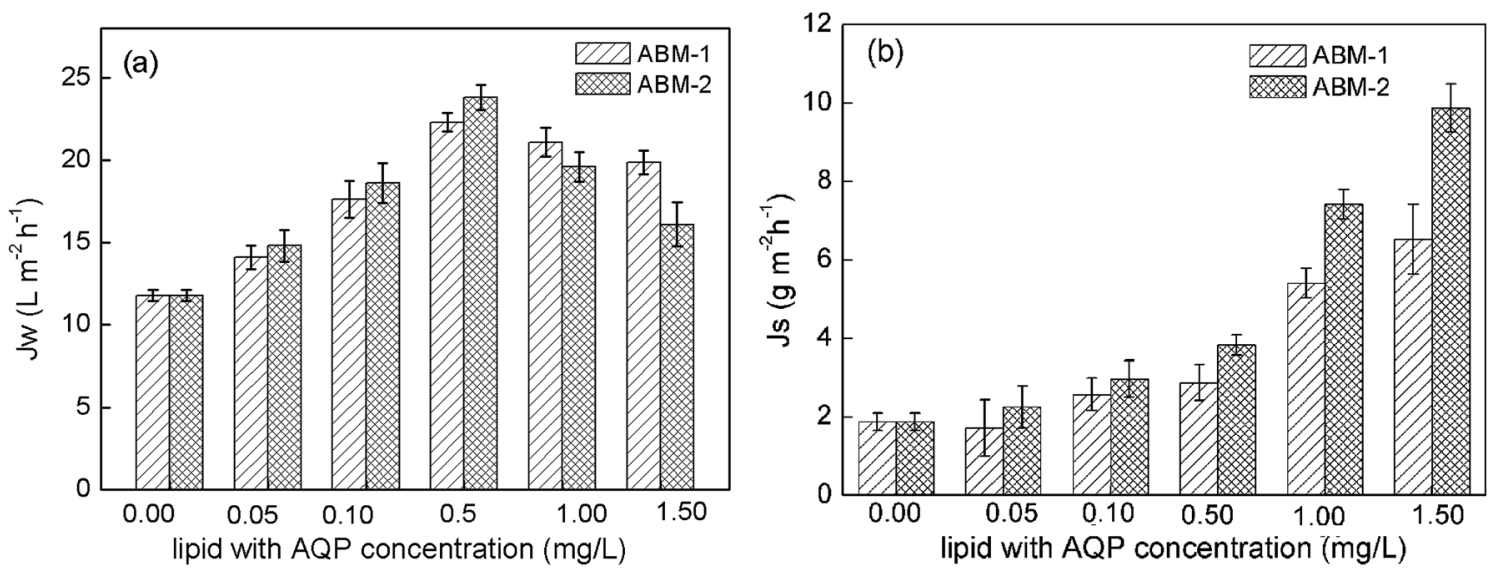

Fig. 7 Performance of ABM-1 and ABM-2 with different proteoliposome concentrations during osmotic testing: (a) water flux and (b) reverse salt flux in the forward osmosis orientation (P/L value was 1 : 200; feed solution: $1 \mathrm{M} \mathrm{NaCl}$; draw solution: DI water; error bar: SD, $n \geq 3$ ).

flux of the ABMs. The normalised water flux and reverse salt flux of the AQP-incorporated membrane with different $\mathrm{NaOCl}$ concentration are shown in Fig. 8. An increase in water flux with respect to the baseline was achieved after $\mathrm{NaOCl}$ treatment, while an insignificant change was observed in the reverse salt flux. It is worth noting that the post-treatment with an appropriate concentration of $\mathrm{NaOCl}$ had a positive effect on the improvement of membrane separation performance, and the risk to protein activity is considered minute and within acceptable limits. During the $\mathrm{NaOCl}$ post-treatment, the $\mathrm{N}-\mathrm{H}$ hydrogen of the membrane material is replaced by chlorine, while the hydrogen bonds between $\mathrm{C}=\mathrm{O}$ and $\mathrm{N}-\mathrm{H}$ are weakened or even destroyed, which makes the membrane more hydrophilic. In addition, the flexibility and rotational freedom of the crosslinked polymer chains increased. ${ }^{42,43}$ These structural changes and the enhanced hydrophilicity of the membrane after $\mathrm{NaOCl}$ post-treatment resulted in an improved water permeability. This indicated that AQPs were almost fully incorporated in the selective layer, which underwent minimal degradation and accorded good protection to the AQPs during the NaOCl post-treatment. The treatment induces a physical change in the polyamide active layer, which consequently exhibited an outstanding performance.

Effect of thermal treatment on forward osmosis performance. The effects of thermal treatment on the ABMs were investigated, and the results are shown in Fig. 9. With an increase in thermal treatment temperature, the water permeability increased slightly, while an approximately $30 \%$ decrease was observed in the reverse salt flux after the thermal treatment. This phenomenon is due to the complete volatilization of $n$ hexane as a solvent for TMC above $68{ }^{\circ} \mathrm{C}$ (boiling point of hexane), resulting in evaporation of bound water inside the membrane after complete evaporation of the organic solvents. Besides, the temperature has a significant influence on the pore size distribution of the membrane, which have been demonstrated by non-equilibrium molecular dynamics (NEMD) simulation. Increased temperature will weaken the hydrogen bonding interactions between the molecular chains and make the pore size distribution more compact, ${ }^{44,45}$ thereby resulting in a compact and dense thin film forward osmosis composite membrane; this membrane structure was helpful in obtaining a low reverse salt flux. ${ }^{46}$ This result also demonstrated that
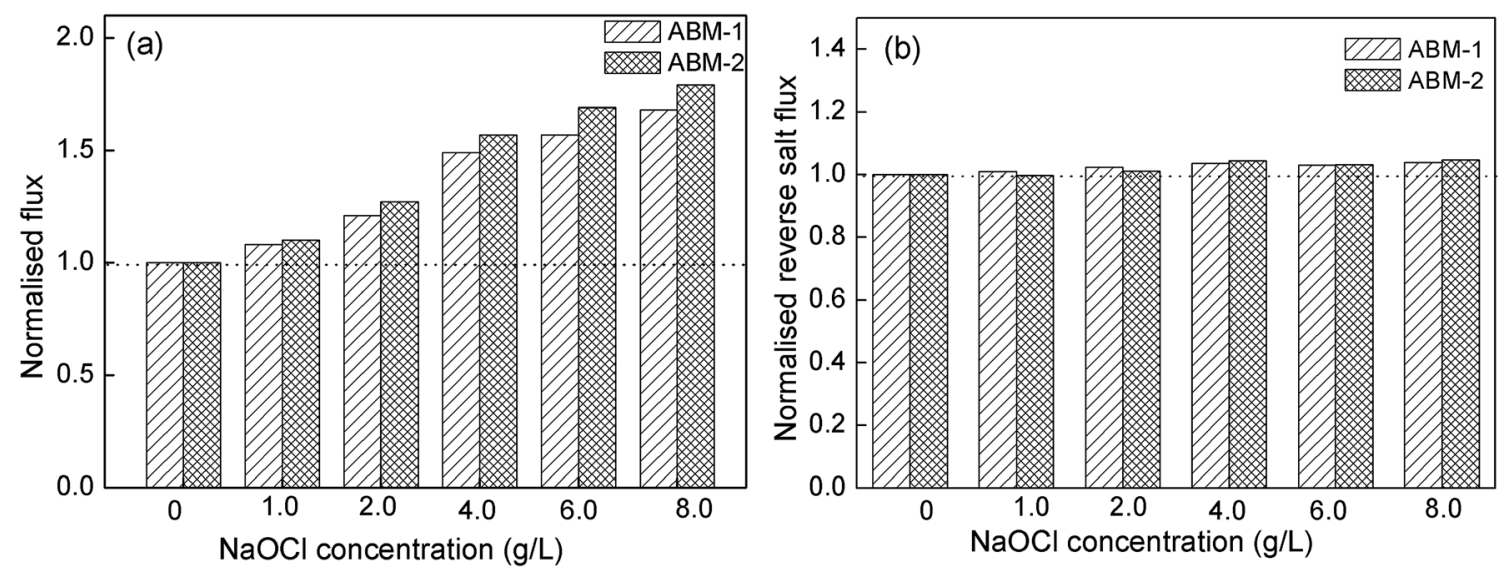

Fig. 8 Normalised water fluxes of ABM-1 and ABM-2 with various $\mathrm{NaOCl}$ concentrations (feed solution: $1 \mathrm{M} \mathrm{NaCl}$; draw solution: DI water). 

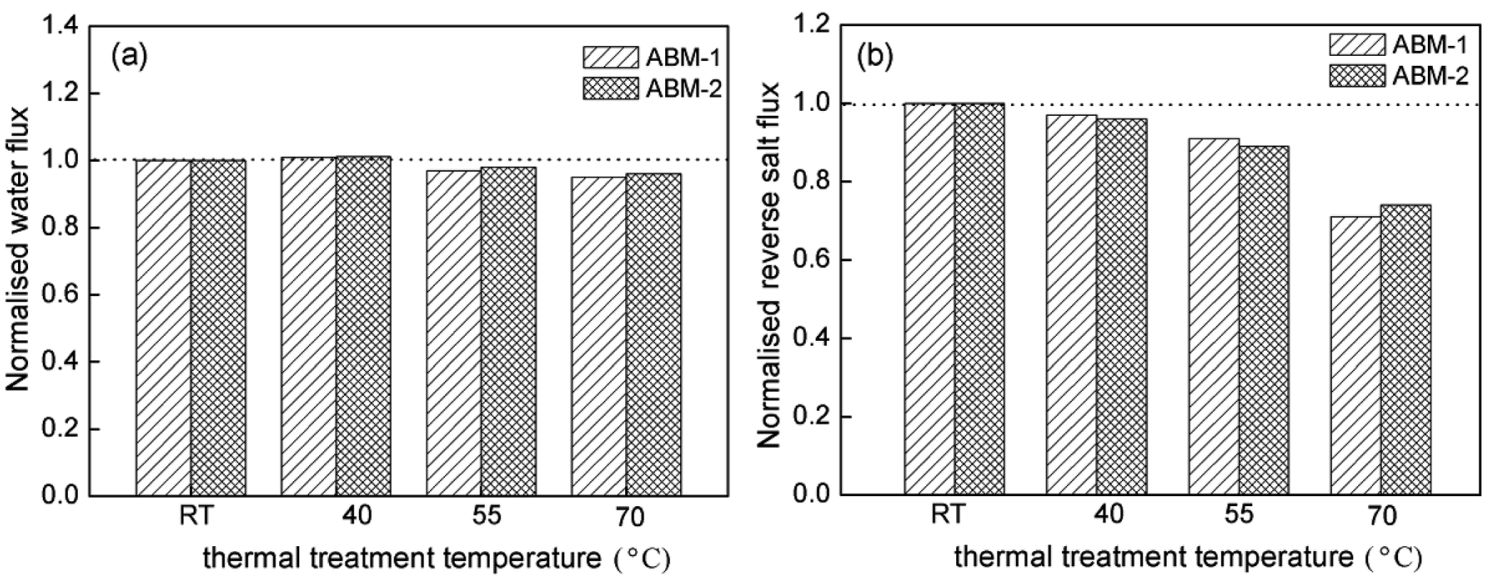

Fig. 9 Normalised water fluxes of ABM-1 and ABM-2 with various thermal treatment temperature (feed solution: $1 \mathrm{M} \mathrm{NaCl}$; draw solution: $\mathrm{DI}$ water).

thermal treatment was beneficial in improving the membrane separation performance and the AQP tetramers were quite stable even in a harsh in vitro environment.

Intrinsic membrane properties. Fig. 10 shows the water fluxes and reverse salt fluxes of ABM-1 and ABM-2 using DI water as the feed and $\mathrm{NaCl}$ draw solutions with concentrations ranging from 0.5 to $2.0 \mathrm{M}$. The water fluxes increased with increasing draw solution concentration. The increasing trend of reverse salt flux for higher draw solution concentrations is caused by the internal concentration polarisation effect and has been well documented. ${ }^{47}$ In this study, the intrinsic water permeance, salt permeability, and structural parameter were evaluated using an empirical method developed by Tiraferri et $a .^{32}$ ABM-1 and ABM-2 exhibited relatively high water permeances and low salt permeabilities and structural parameters compared with those of some previously reported TFC membranes summarised in Table 2. The AQP-incorporated proteoliposomes can be considered as highly water-permeable vesicles that facilitate the transport in a selective layer, thus contributing to an excellent membrane separation performance. The membrane structural parameter is an intrinsic membrane parameter used to determine the degree of internal concentration polarisation in the porous support structure of a forward osmosis membrane and is crucial for the evaluation of forward osmosis membrane performance. ${ }^{48,49}$ ABM-1 exhibited a much lower structural parameter than that of ABM-2. It is noteworthy that an increase in structural parameter adversely affects the forward osmosis performance, whereas an increase in water permeance results in an improved water flux. The strategy for producing ABM-1 may contribute to a thinner and less defective polyamide selective layer compared with $\mathrm{ABM}-2$, in which the PSf substrate surface is soaked in an $\mathrm{m}$ phenylenediamine aqueous solution containing AQP proteoliposomes rather than sequential soaking in an $m$-phenylenediamine aqueous followed by a proteoliposome solution.

\section{Membrane stability}

The stability of biomimetic membrane in real applications is a major concern as protein activity may suffer from instability over time or chemical cleaning. To investigate the stability of
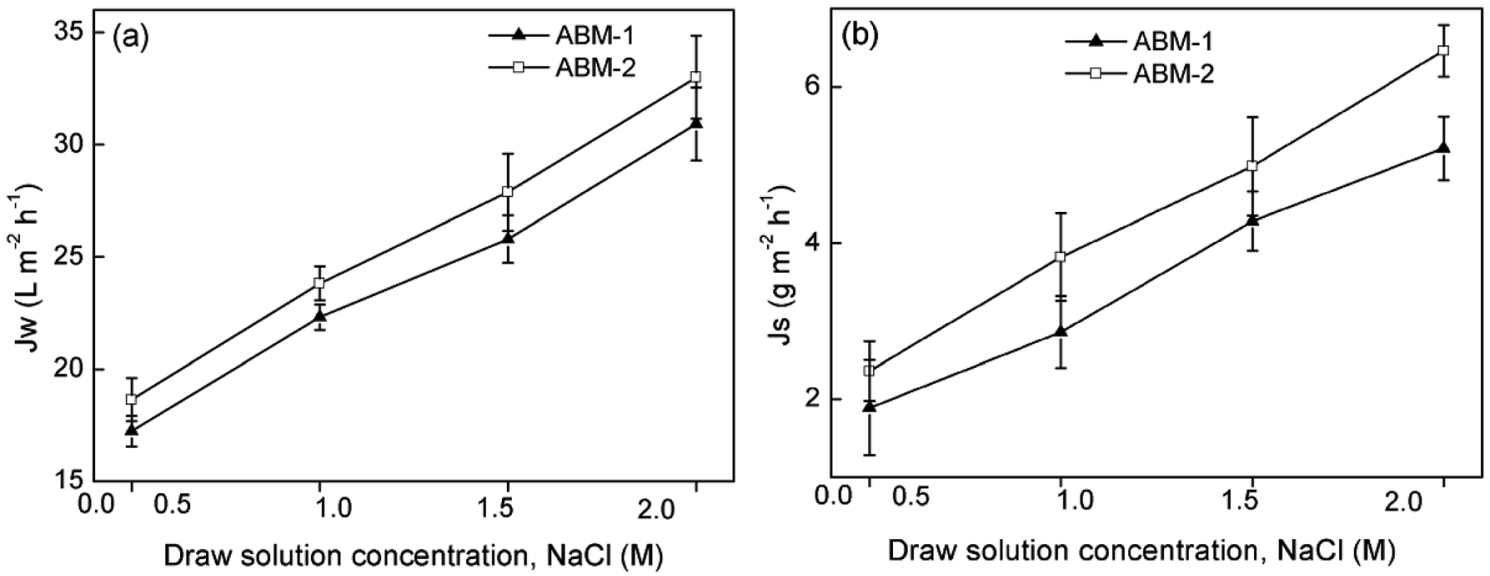

Fig. 10 Experimental (a) water flux and (b) reverse salt flux data of ABM-2 and ABM-1 in forward osmosis mode using DI water feed solutions and $\mathrm{NaCl}$ draw solutions of varying concentrations $\left(P / L\right.$ ratio $=1 / 200$; lipid with a proteoliposome concentration of $0.5 \mathrm{mg} \mathrm{L}^{-1}$ ). 
Table 2 Comparison of aquaporin-based biomimetic membranes with some other reported biomimetic thin film composite membranes

\begin{tabular}{|c|c|c|c|c|c|c|c|c|c|c|}
\hline & Membrane type & $\begin{array}{l}\text { Feed } \\
\text { solution }\end{array}$ & $\begin{array}{l}\text { Draw } \\
\text { solution }\end{array}$ & $\begin{array}{l}\text { Water flux } \\
\left(\mathrm{L} \mathrm{m}^{-2} \mathrm{~h}^{-1}\right)\end{array}$ & $\begin{array}{l}\text { Reverse salt } \\
\text { flux } \\
\left(\mathrm{L} \mathrm{m} \mathrm{m}^{-2} \mathrm{~h}^{-1}\right)\end{array}$ & $\begin{array}{l}J_{\mathrm{s}} / J_{\mathrm{w}} \\
\left(\mathrm{g} \mathrm{L}^{-1}\right)\end{array}$ & $A(\mathrm{LMH}$ per bar $)$ & $B(\mathrm{LMH})$ & $S(\mu \mathrm{m})$ & References \\
\hline 1 & ABM-1 & DI & $1 \mathrm{M} \mathrm{NaCl}$ & 22.31 & 2.87 & & 0.73 & 0.08 & 153 & This work \\
\hline 2 & $\mathrm{ABM}-2$ & DI & $1 \mathrm{M} \mathrm{NaCl}$ & 22.82 & 3.82 & & 0.87 & 0.12 & 188 & This work \\
\hline 3 & $\begin{array}{l}\text { AQP-TFC(Hehqp) } \\
\text { flat sheet membrane }\end{array}$ & DI & $0.8 \mathrm{M} \mathrm{NaCl}$ & 5.38 & ND & ND & 5.38 & 49.26 & ND & 20 \\
\hline 4 & $\begin{array}{l}\text { AQP-(PA)TFC flat sheet } \\
\text { membrane }\end{array}$ & DI & $1 \mathrm{M} \mathrm{NaCl}$ & 23.10 & 4.4 & 0.19 & 6.6 & 1.7 & 420 & 50 \\
\hline 5 & $\begin{array}{l}\text { Aquaporin A/S flat sheet } \\
\text { membrane }\end{array}$ & DI & $1 \mathrm{M} \mathrm{NaCl}$ & 2.09 & 0.07 & 0.03 & ND & ND & ND & 8 \\
\hline 6 & $\begin{array}{l}\text { Aquaporin A/S hollow fibre } \\
\text { membrane }\end{array}$ & DI & $1 \mathrm{M} \mathrm{NaCl}$ & 13.2 & 1.7 & 0.13 & 0.43 & 0.05 & 210 & 51 \\
\hline 7 & $\begin{array}{l}\text { AQP-TFC-HF-PEI hollow fibre } \\
\text { membrane }\end{array}$ & DI & $1 \mathrm{M} \mathrm{NaCl}$ & 49.1 & 4.7 & 0.95 & ND & ND & ND & 33 \\
\hline 8 & $\begin{array}{l}\text { PA@Psf/LDH TFNC flat sheet } \\
\text { membrane }\end{array}$ & DI & $1 \mathrm{M} \mathrm{NaCl}$ & 18.1 & 8.1 & 0.44 & 0.61 & 0.27 & 148 & 49 \\
\hline 9 & PES-TFC hollow fibre membrane & DI & $0.5 \mathrm{M} \mathrm{NaCl}$ & 18.6 & 2.0 & 0.11 & 3.29 & 0.11 & 490 & 52 \\
\hline
\end{tabular}
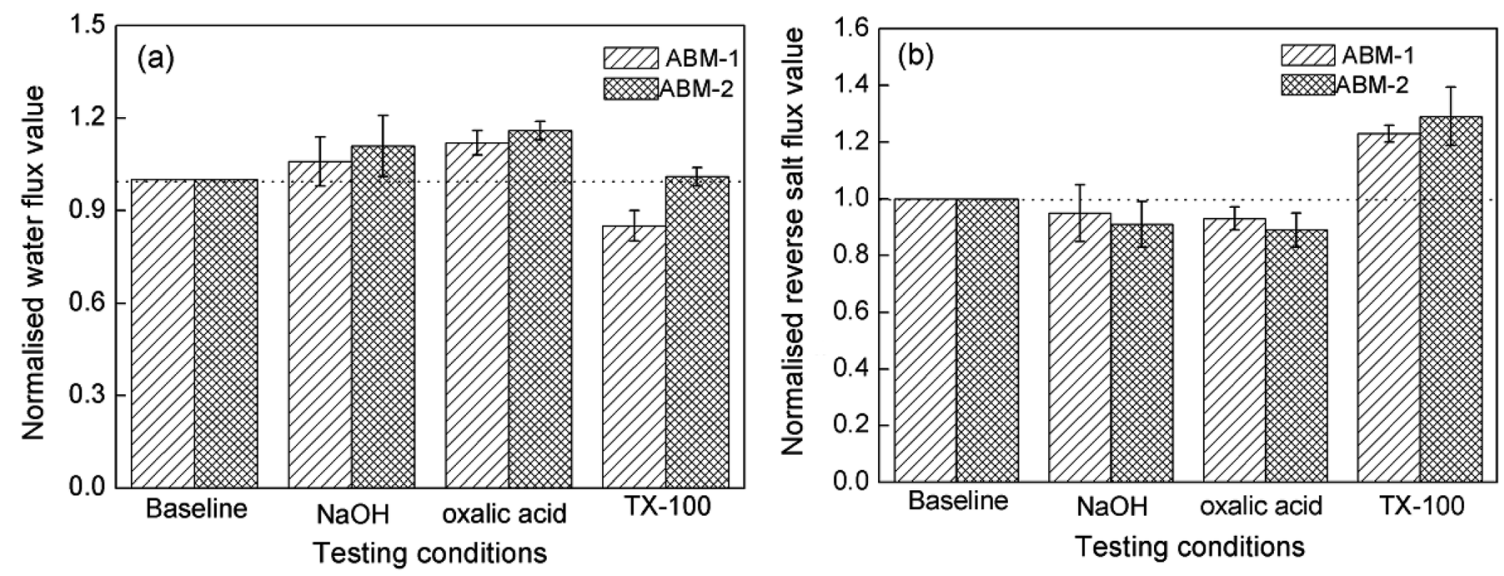

Fig. 11 Normalised water fluxes $\left(J_{w}\right)$ and normalised reverse salt fluxes $\left(J_{s}\right)$ of $A B M-1$ and $A B M-2$ after soaking in $\mathrm{NaOH}(\mathrm{pH}=11)$, oxalic acid $(\mathrm{pH}$ $=3$ ), and TX-100 (Triton-100 solution: $0.25 \mathrm{mM}$; soaked for $2 \mathrm{~h}$ ).

the AQP membrane, a chemical cleaning test was conducted using different agents ( $\mathrm{NaOH}$, oxalic acid, and TX-100). $\mathrm{NaOH}$ can dissolve the weakly acidic organic matter, while oxalic acid dissolves the minerals from the fouling layers, and TX-100 is a commonly used non-ionic detergent. ${ }^{53}$ Fig. 11(a) displays the normalised water flux for the baseline experiment. A minor change in water permeability or reverse salt flux for both ABM-1 and $\mathrm{ABM}-2$ was observed after chemical cleaning. The water permeability slightly increased after the membrane was soaked in $\mathrm{NaOH}$ and oxalic acid solutions, while the reverse salt flux slightly decreased. The amide I bond $(-\mathrm{C}=\mathrm{O})$ of the polymer layer may be hydrolysed into the $-\mathrm{COO}^{-}$group when the membranes are soaked in $\mathrm{NaOH}$ solution, leading to a more hydrophilic and negatively charged surface, which can be attributed to an increase in water flux and reverse salt flux. ${ }^{54}$ When the active layer of the membrane was cleaned using a TX100 solution, ABM-2 showed a more obvious decrease in water flux and an increase in reverse salt flux compared with ABM-1, indicating that ABM-1 was more durable to chemical rinsing.
TX-100 is often used in membrane protein extraction and may affect the lipid bilayer and induce many defects. These results confirmed that the proteoliposome-containing polyamide layer remains relatively stable under those chemical environments and the strategy for producing ABM-1 has better ability of protecting the liposomes from chemical environments.

\section{Conclusions}

In the present work, a highly permeable and selective membrane based on AQPs was developed by incorporating proteoliposomes into a polyamide layer via the interfacial polymerisation method. $\mathrm{NaOCl}$ post-treatment and thermal treatment were beneficial in enhancing the water permeability and reducing the salt permeability, respectively. It was observed that $\mathrm{ABM}-1$ with a $\mathrm{P} / \mathrm{L}$ ratio of $1 / 200$ and $0.5 \mathrm{mg} \mathrm{L}^{-1}$ proteoliposomes achieved a high water flux $\left(22.31 \mathrm{~L} \mathrm{~m}^{-2} \mathrm{~h}^{-1}\right)$ and a low reverse salt flux $\left(2.87 \mathrm{~g} \mathrm{~m}^{-2} \mathrm{~h}^{-1}\right)$. The prepared membrane exhibited water flux and reverse salt flux comparable to those of 
previously reported thin film forward osmosis composite membranes. The results confirmed that the addition of AQPs contributed to the enhanced water flux and salt rejection. The synthetic protocol of the prepared ABM-1 was found beneficial in reducing the formation of defects and the membrane exhibited a better salt rejection and chemical stability than those of ABM-2.

\section{Conflicts of interest}

There are no conflicts to declare.

\section{Acknowledgements}

This work was financially supported by the National Science Foundation of China (Grant No. 21376030), the National Research Foundation of Korea (NRF) grant funded by the Korea government (MSIT) (No. 2019R1C1C1006310 and 2019R1A2C1002844) and the Ministry of Education (No. 2016R1A6A1A03012877).

\section{Notes and references}

1 T. H. Chong, F. S. Wong and A. G. Fane, Implications of critical flux and cake enhanced osmotic pressure (CEOP) on colloidal fouling in reverse osmosis: experimental observations, J. Membr. Sci., 2008, 314, 101-111.

2 N. Misdan, W. J. Lau and A. F. Ismail, Seawater reverse osmosis (SWRO) desalination by thin-film composite membrane-current development, challenges and future prospects, Desalination, 2012, 287, 228-237.

3 T. Y. Cath, A. E. Childress and M. Elimelech, Forward osmosis: principles, applications and recent developments, J. Membr. Sci., 2006, 281, 70-87.

4 (a) W. Sun, J. Shi, C. Chen, N. Li, Z. Xu, J. Li, H. Lv, X. Qian and L. Zhao, A review on organic-inorganic hybrid nanocomposite membranes: a versatile tool to overcome the barriers of forward osmosis, RSC Adv., 2018, 8, 1004010056; (b) N. Akther, A. Sodiq, A. Giwa, S. Daer, A. H. Arafat and S. W. Hasan, Recent advancements in forward osmosis desalination: a review, Chem. Eng. J., 2015, 281, 502-522.

5 L. B. Yang, Z. Wang, J. L. Zhang, P. Song and P. Liu, TIPS-coNIPS method to prepare PES substrate with enhanced permeability for TFC-FO membrane, J. Taiwan Inst. Chem. Eng., 2017, 80, 137-148.

6 K. H. Chan, E. T. Wong, M. Irfan, A. Idris and N. M. Yusof, Enhanced $\mathrm{Cu}(\mathrm{II})$ rejection and fouling reduction through fabrication of PEG-PES nanocomposite ultrafiltration membrane with PEG-coated cobalt doped iron oxide nanoparticle, J. Taiwan Inst. Chem. Eng., 2015, 47, 50-58.

7 F. Li, F. Zhao and M. Huang, Thin-film composite membranes with nanocomposite substrate modified with graphene oxide/ $\mathrm{TiO}_{2}$ for forward osmosis process, Desalin. Water Treat., 2017, 70, 64-78.

8 M. R. Mahdavi, M. Delnavaz and V. Vatanpou, Fabrication and water desalination performance of piperazine- polyamide nanocomposite nanofiltration membranes embedded with raw and oxidized MWCNTs, J. Taiwan Inst. Chem. Eng., 2017, 75, 189-198.

$9 \mathrm{~J}$. R. Werber and M. Elimelech, Permselectivity limits of biomimetic desalination membranes, Sci. Adv., 2018, 4, 1-9. 10 W. Luo, M. Xie, X. Song, W. Guo, H. H. Ngo, J. L. Zhou and L. D. Nghiem, Biomimetic aquaporin membranes for osmotic membrane bioreactors: membrane performance and contaminant removal, Bioresour. Technol., 2017, 249, 62-68.

11 S. L. Wang, A. Yoshinari, T. Shimada, I. Hara-Nishimura, N. Mitani-Ueno, J. F. Ma, S. Naito and J. Takano, Polar Localization of the NIP5;1 Boric Acid Channel Is Maintained by Endocytosis and Facilitates Boron Transport in Arabidopsis Roots, Plant Cell, 2017, 29(4), 824-842.

12 C. Maurel, Y. Boursiac, D. T. Luu, V. Santoni, Z. Shahzad and L. Verdoucq, Aquaporins in plants, Physiol. Rev., 2015, 95(4), 1321-1358.

13 D. M. Warsinger, S. Chakraborty, E. W. Tow, M. H. Plumlee, C. Bellona, S. Loutatidou, L. Kaeimi, A. M. Mikelonis, A. Achilli, A. Ghassemi, L. P. Padhye, S. A. Snyder, S. Curcio, C. D. Vecitis, H. A. Arafat and V. J. H. Lienhard, A review of polymeric membranes and processes for potable water reuse, Prog. Polym. Sci., 2018, 81, 209-237.

14 A. Giwa, S. W. Hasan, A. Yousuf, S. Chakraborty, D. J. Johnson and N. Hilal, Biomimetic membranes: a critical review of recent progress, Desalination, 2017, 420, 403-424.

15 C. Tang, Z. Wang, I. Petrinić, A. G. Fane and C. Hélix-Nielsen, Biomimetic aquaporin membranes coming of age, Desalination, 2015, 368, 89-105.

16 Z. Yang, X. H. Ma and C. Y. Tang, Recent development of novel membranes for desalination, Desalination, 2018, 434, 37-59.

17 Y. Wang, P. P. Gorecki, E. Stamate, K. Norrman, D. Aili, M. Zuo, W. Guo and C. Helix-Nielsen, Preparation of super-hydrophilic polyphenylsulfone nanofiber membranes for water treatment, RSC Adv., 2019, 9, 278-286.

18 X. S. Li, R. Wang, C. Y. Tang, A. Vararattanavech, Y. Zhao, J. Torres and T. Fane, Preparation of supported lipid membranes for aquaporin $\mathrm{Z}$ incorporation, Colloids Surf., B, 2012, 94, 333-340.

19 W. Ding, J. Cai and Z. Yu, Fabrication of an aquaporin-based forward osmosis membrane through covalent bonding of a lipid bilayer to a microporous support, J. Mater. Chem. A, 2015, 3, 20118-20126.

20 X. Li, R. Wang, C. Tang, A. Vararattanavech, Y. Zhao, J. Torres and T. Fane, Fusion behaviour of aquaporin $\mathrm{Z}$ incorporated proteoliposomes investigated by quartz crystal microbalance with dissipation (QCM-D), Colloids Surf., B, 2013, 111, 446-452.

21 N. G. Calicioglu, G. O. Ozdemir, A. Ozturk, A. Yildiz, H. Yilmaz, P. Ergenekon, M. Erbakan, E. Erhan and M. Ozkan, Use of halophilic aquaporin for preparation of biomimetic thin film composite membrane, J. Membr. Sci., 2018, 568, 105-112. 
22 Y. X. Shen, P. O. Saboe, I. T. Sines, M. Erbakan and M. Kumar, Biomimetic membranes: a review, J. Membr. Sci., 2014, 454, 359-381.

23 H. L. Wang, T. S. Chung, Y. W. Tong, K. Jeyaseelan and A. Armugam, Mechanically robust and highly permeable aquaporin Z biomimetic membranes, J. Membr. Sci., 2013, 434, 130-136.

24 G. Sun, T. S. Chung, K. Jeyaseelan and A. Armugam, A layerby-layer self-assembly approach to developing an aquaporinembedded mixed matrix membrane, RSC Adv., 2013, 3, 473481.

25 Y. Zhao, N. Gao, Y. F. Feng, H. Shi, W. Sun, K. K. Shen, Y. B. Wang, S. Q. Shi and Y. K. Gong, Fabrication of robust biomimetic coating by integrated physisorption/chemical crosslinking technique, Appl. Surf. Sci., 2018, 453, 37-43.

26 W. Y. Xie, F. He, B. F. Wang, T. S. Chung, K. Jeyaseelan, A. Armugam and Y. W. Tong, An aquaporin-based vesicleembedded polymeric membrane for low energy water filtration, J. Mater. Chem. A, 2013, 1(26), 7592-7600.

27 S. Qi, R. Wang, G. K. M. Chaitra, J. Torres, X. Hu and A. G. Fane, Aquaporin-based biomimetic reverse osmosis membranes: stability and long term performance, $J$. Membr. Sci., 2016, 508(15), 94-103.

28 H. W. Zhang, Thin-Film Hydration Followed by Extrusion Method for Liposome Preparation, Methods Mol. Biol., 2017, 1522, 17-22.

29 J. S. Hansen, A. Vararattanavech, I. Plasencia, P. J. Greisen, J. Bomholt, J. Torres, J. Emneus and C. Helix-Nielsen, Interaction between sodium dodecyl sulfate and membrane reconstituted aquaporins: a comparative study of spinach SoPIP2;1 and E. coli AqpZ, Biochim. Biophys. Acta, 2011, 1808, 2600-2607.

30 M. J. Borgnia, D. Kozono, G. Calamita, P. C. Maloney and P. Agre, Functional reconstitution and characterization of AqpZ, the E-coli water channel protein, J. Mol. Biol., 1999, 291, 1169-1179.

31 G. Han, T. S. Chung, M. Toriida and S. Tamai, Thin-film composite forward osmosis membranes with novel hydrophilic supports for desalination, J. Membr. Sci., 2012, 423-424, 543-555.

32 A. Tiraferri, N. Y. Yip, A. P. Straub, R. V. Castrillon and M. Elimelech, A method for the simultaneous determination of transport and structural parameters of forward osmosis membranes, J. Membr. Sci., 2013, 444, 523-538.

33 X. Li, C. H. Loh, R. Wang, W. Widjajanti and J. Torres, Fabrication of a robust high-performance FO membrane by optimizing substrate structure and incorporating aquaporin into selective layer, J. Membr. Sci., 2017, 525, 257-268.

34 M. Wang, W. Yu, Y. Zhang, J. Y. Woo, Y. Chen, B. Wang, Y. Yun, G. Liu, J. K. Lee and L. Wang, A novel flexible micro-ratchet/ZnO nano-rods surface with rapid recovery icephobic performance, J. Ind. Eng. Chem., 2018, 62, 52-57.

35 L. Wang, J. Lu, M. Wang, B. Zhang, Y. Hou, G. Liu, W. Yang and J. Liu, Anti-fogging performances of liquid metal surface modified by ZnO nano-petals, J. Taiwan Inst. Chem. Eng., 2019, 95, 65-70.

36 M. Wang, Z. Wang, Z. Wang, S. Wang, W. Ding and C. Gao, Layer-by-layer assembly of aquaporin Z-incorporated biomimetic membranes for water purification, Environ. Sci. Technol., 2015, 49, 3761-3768.

37 M. X. Wang, G. C. Liu, H. Yu, S. H. Lee, L. Wang, J. Zheng, T. Wang, Y. Yun and J. K. Lee, ZnO Nanorod Array Modified PVDF Membrane with Superhydrophobic Surface for Vacuum Membrane Distillation Application, ACS Appl. Mater. Interfaces, 2018, 10(16), 13452-13461.

38 S. C. Xu, Y. Q. Liu, Y. Wang, M. K. Zhang, Q. Q. Xiao and Y. W. Duan, Influential analysis of concentration polarization on water flux and power density in PRO process: modeling and experiments, Desalination, 2017, 412, 39-48.

39 P. Wagh, G. Parungao, R. E. Viola and I. C. Escobar, A new technique to fabricate high-performance biologically inspired membranes for water treatment, Sep. Purif. Technol., 2015, 156, 754-765.

40 Y. Zhao, A. Vararattanavech, X. Li, C. Hélixnielsen, T. Vissing, J. Torres, R. Wang, A. G. Fang and C. Y. Tang, Effects of proteoliposome composition and draw solution types on separation performance of aquaporin-based proteoliposomes: implications for seawater desalination using aquaporin-based biomimetic membranes, Environ. Sci. Technol., 2013, 47, 1496-1503.

41 Z. Wang, X. Wang, W. Ding, M. Wang, X. Qi and C. Gao, Impact of monoolein on aquaporin1-based supported lipid bilayer membranes, Sci. Technol. Adv. Mater., 2015, 16, 045005.

42 X. F. Zhai, J. Q. Meng, R. Li, L. Ni and Y. F. Zhang, Hypochlorite treatment on thin film composite RO membrane to improve boron removal performance, Desalination, 2011, 274, 136-143.

43 V. T. Do, C. Y. Tang, M. Reinhard and J. O. Leckie, Degradation of polyamide nanofiltration and reverse osmosis membranes by hypochlorite, Environ. Sci. Technol., 2012, 46, 852-859.

44 K. Li, L. Liu, H. Wu, S. Li, C. Yu, Y. Zhou, W. Huang and D. Yan, Understanding the temperature effect on transport dynamics and structures in polyamide reverse osmosis system via molecular dynamics simulations, Phys. Chem. Chem. Phys., 2018, 20, 29996-30005.

45 M. Shen, S. Keten and R. M. Lueptow, Dynamics of water and solute transport in polymeric reverse osmosis membranes via molecular dynamics simulations, J. Membr. Sci., 2016, 506, 95-108.

46 P. R. Buch, D. J. Mohan and A. V. R. Reddy, Preparation, characterization and chlorine stability of aromaticcycloaliphatic polyamide thin film composite membranes, J. Membr. Sci., 2008, 309(1-2), 36-44.

47 P. Hajighahremanzadeh, M. Abbaszadeh, S. A. Mousavi, M. Soltanieh and H. Bakhshi, Polyamide/polyacrylonitrile thin film composites as forward osmosis membranes, $J$. Appl. Polym. Sci., 2016, 133, 44130. 
48 X. Li, R. Wang, F. Wicaksana, C. Tang, J. Torres and A. G. Fane, Preparation of high performance nanofiltration (NF) membranes incorporated with aquaporin Z, J. Membr. Sci., 2014, 450, 181-188.

49 P. Lu, S. Liang, L. Qiu, Y. Gao and Q. Wang, Thin film nanocomposite forward osmosis membranes based on layered double hydroxide nanoparticles blended substrates, J. Membr. Sci., 2016, 504, 196-205.

50 Y. Chuna, L. Qing, G. F. Sun, M. R. Bilad, A. G. Fane and T. H. Chong, Prototype aquaporin-based forward osmosis membrane: Filtration properties and fouling resistance, Desalination, 2018, 445, 75-84.

$51 \mathrm{~J}$. Ren and J. R. McCutcheon, A new commercial biomimetic hollow fiber membrane for forward osmosis, Desalination, 2018, 442, 44-50.
52 L. Shi, S. R. Chou, R. Wang, W. X. Fang, C. Y. Tang and A. G. Fane, Effect of substrate structure on the performance of thin-film composite forward osmosis hollow fiber membranes, J. Membr. Sci., 2011, 382(1-2), 116-123.

53 L. Shi-Yow, A. Casandra, Y. Y. Margaretha and R. Y. Tsay, Impingement of Triton X-100 solution drops on paraffin film-Relaxation of surface dilational rate, J. Taiwan Inst. Chem. Eng., 2018, 92, 36-41.

54 M. Mänttäri, A. Pihlajamäki and M. Nyström, Effect of pH on hydrophilicity and charge and their effect on the filtration efficiency of NF membranes at different pH, J. Membr. Sci., 2006, 280, 311-320. 